\section{Two new separation schemes for the group isolation of rare earth elements (REE) from biological and other matrices and their determination by ICP-MS, NAA and chromatographic methods}

Rajmund S. Dybczyński, Zbigniew Samczyński, Iwona Bartosiewicz, Krzysztof Kulisa, Halina Polkowska-Motrenko, Marta Pyszynska, Iga Zuba

Abstract. Two new group separation schemes, based on ion exchange chromatography, for the selective and quantitative isolation of rare earth elements (REE) from accompanying elements, were devised. After checking their performance with the aid of radioactive tracers, the schemes were further used together with ICP-MS, NAA and ion exchange chromatography for the determination of Sc, Y, La, Ce, Pr, Nd, Sm, Eu, Gd, Tb, Dy, Ho, Er, $\mathrm{Tm}, \mathrm{Yb}$ and $\mathrm{Lu}$ in two certified reference materials (CRMs). The results were compared with another series of analyses, where the REEs were determined directly, i.e. without pre-separation, by instrumental neutron activation analysis (INAA) and inductively coupled plasma mass spectrometry (ICP-MS). It was demonstrated that while direct INAA and ICP-MS in most instances provide reliable results for the majority of REEs, for some elements, notably Sc, Yb and Tm in the cases of ICP-MS and INAA, respectively, systematic errors occur or may potentially occur.

Keywords: rare earth elements (REE) • lanthanides • ion exchange chromatography • NAA • ICP-MS • accuracy $\bullet$ certified reference materials (CRM)

R. S. Dybczyński ${ }^{\bowtie}$, Z. Samczyński, I. Bartosiewicz, K. Kulisa, H. Polkowska-Motrenko, M. Pyszynska, I. Zuba

Laboratory of Nuclear Analytical Methods, Institute of Nuclear Chemistry and Technology, 16 Dorodna Str., 03-195 Warsaw, Poland, Tel.: +48 22504 1076, Fax: +48 22811 1532, E-mail: r.dybczynski@ichtj.waw.pl

Received: 18 November 2016

Accepted: 9 February 2017

\section{Introduction}

Rare earth elements (REEs), i.e. Sc, Y, La and the lanthanides, constitute an interesting group of 17 elements of extremely similar chemical properties that make their separation and analytical determination difficult. One of the lanthanides - promethium - has no stable isotope and does not occur naturally.

REEs are elements of steadily growing importance in science and in various branches of technology. They are used as catalysts, components of alloys, for the production of phosphors for colour TVs, in electronics, lasers, superconductors, permanent magnets, etc. [1-3]. Studying the distribution of REEs in rocks, sediments and meteorites is important for the theoretical interpretation of geological processes [4].

Over the last three decades there has been an increasing interest in the role of REEs in the Life Sciences, because they were used in agriculture to increase crop production and improve animal husbandry $[5,6]$. Some workers suggested that REEs which enter plants may subsequently via the food chain be ingested by animals and humans and participate in cellular processes, e.g. by replacing certain biometals like calcium in organic molecules 
like chelates [7, 8]. In this regard attention was drawn to the fact that as biological processes are very selective, various REEs may behave in different ways depending on their ionic size [9]. Hence the need to determine all the members of the REE group may appear to be very important in several future studies.

Only a few analytical methods, namely inductively coupled plasma mass spectrometry (ICP-MS), neutron activation analysis (NAA), inductively coupled plasma atomic emission spectrometry (ICP-AES) and X-ray fluorescence (XRF) [10-12], have the potential to accurately determine all or most of the members of the REE group at trace and ultra-trace levels $\left(10^{-7}-10^{-9} \mathrm{~g} \cdot \mathrm{g}^{-1}\right)$. Each of these methods may suffer from matrix effects and various kinds of interferences depending on the kind of materials being analysed. Therefore, some of the authors emphasized that the pre-separation of the REE group from most of the matrix elements is beneficial to fully exploit the capabilities of each method.

The purpose of this work was to elaborate two independent separation schemes based on ion exchange chromatography for the selective and quantitative isolation of the REE group from accompanying elements and to use them for REE determination in materials of biological and geological origin by employing available analytical techniques. It was hoped that by using suitable certified reference materials (CRMs) the comparison of results with those obtained by direct methods (without the use of REE pre-separation) would enable the identification of possible sources of systematic errors.

\section{Experimental}

Ion exchange resins, radioactive tracers, certified reference materials, reagents

The following ion exchange resins were used in this study: macroporous amphoteric Purolite $\mathrm{S} 950\left[\mathrm{H}^{+}\right]$ with aminophosphonic groups and particle size fractions of 35-65 and 50-100 $\mu \mathrm{m}$ (Purolite International Ltd.); gel-type amphoteric Chelex $100\left[\mathrm{H}^{+}\right]$with iminodiacetic acid groups, 200-400 mesh (Bio-Rad Laboratories); gel-type amphoteric Retardion 11A8 particle size 49-92 $\mu \mathrm{m}$ (Bio-Rad Laboratories); gel-type strongly acidic Dowex 50WX8, 100-200 mesh and 200-400 mesh (Bio-Rad Laboratories); gel-type strongly basic anion exchange Dowex $1 \mathrm{X} 4\left[\mathrm{Cl}^{-}\right]$, 100-200 mesh (Serva Feinbiochemika). All these resins were of analytical grade. Additional purification was applied by successively passing through a column with a given ion exchanger a large excess of $1 \mathrm{M} \mathrm{HCl}\left(\right.$ or $\mathrm{HNO}_{3}$ ) $, \mathrm{H}_{2} \mathrm{O}, 1 \mathrm{M} \mathrm{NaOH}, \mathrm{H}_{2} \mathrm{O}$, and $1 \mathrm{M} \mathrm{HCl}\left(\right.$ or $\mathrm{HNO}_{3}$ ).

The following certified reference materials (CRMs) were used in this study: Tea Leaves INCT-TL-1 (Institute of Nuclear Chemistry and Technology, Warsaw, Poland) and Chinese Stream Sediment NCS DC73316 (National Analysis Center for Iron and Steel, Beijing, China). The moisture content in CRMs was determined according to recommendations of the manufacturers.
Hydrochloric and nitric acids of analytical grade were additionally purified by a quartz sub-boiling distillation system. Moreover, $48 \% \mathrm{HBr}(\mathrm{POCH}$, Poland), 40\% HF (Merck Millipore Co.), $30 \% \mathrm{H}_{2} \mathrm{O}_{2}$ (Chempur, Poland) and $30 \% \mathrm{NH}_{4} \mathrm{OH}$ (Chempur, Poland) were applied. All other reagents used in this study were of analytical grade. Ultra-pure $(18 \mathrm{M} \Omega \cdot \mathrm{cm})$ water was obtained from the Milli-Q RG Ultrapure Water System (Merck Millipore Co.).

The following radioactive tracers were used during the elaboration of the separation schemes: ${ }^{140} \mathrm{La}\left(T_{1 / 2}=40 \mathrm{~h}\right),{ }^{141} \mathrm{Ce}\left(T_{1 / 2}=32.5 \mathrm{~d}\right),{ }^{142} \operatorname{Pr}\left(T_{1 / 2}=\right.$ $19.2 \mathrm{~h}),{ }^{147} \mathrm{Nd}\left(T_{1 / 2}=11.1 \mathrm{~d}\right),{ }^{153} \mathrm{Sm}\left(T_{1 / 2}=47 \mathrm{~h}\right)$, ${ }^{152} \mathrm{Eu}\left(T_{1 / 2}=12.2 \mathrm{y}\right),{ }^{160} \mathrm{~Tb}\left(T_{1 / 2}=73 \mathrm{~d}\right),{ }^{171} \mathrm{Er}\left(T_{1 / 2}\right.$ $=7.8 \mathrm{~h}),{ }^{170} \mathrm{Tm}\left(T_{1 / 2}=129 \mathrm{~d}\right),{ }^{175} \mathrm{Yb}\left(T_{1 / 2}=101 \mathrm{~h}\right)$, ${ }^{169} \mathrm{Yb}\left(T_{1 / 2}=30.6 \mathrm{~d}\right),{ }^{177} \mathrm{Lu}\left(T_{1 / 2}=6.75 \mathrm{~d}\right),{ }^{46} \mathrm{Sc}\left(T_{1 / 2}\right.$ $=83.9 \mathrm{~d}),{ }^{60} \mathrm{Co}\left(T_{1 / 2}=5.24 \mathrm{y}\right),{ }^{65} \mathrm{Zn}\left(T_{1 / 2}=245 \mathrm{~d}\right)$, ${ }^{133} \mathrm{Ba}\left(T_{1 / 2}=10.54 \mathrm{y}\right),{ }^{18} \mathrm{Hf}\left(T_{1 / 2}=44.6 \mathrm{~d}\right)$. All tracers were prepared by neutron irradiation of spectrally pure oxides or salts (mostly nitrates) in the Maria Polish reactor (neutron flux $\sim 10^{14} \mathrm{n} \cdot \mathrm{cm}^{-2} \cdot \mathrm{s}^{-1}$ ).

\section{Batch equilibrium measurements}

Weight distribution coefficients, $\lambda$ (amount per $g$ of dry ion exchange resin/amount per $\mathrm{mL}$ of the solution), were determined by batch equilibration at temperatures between 25 and $85^{\circ} \mathrm{C}$. A known amount of the resin (ca. $0.2 \mathrm{~g}$ ) was placed in a conical flask together with $10 \mathrm{~mL}$ of the solution of appropriate composition containing a mixture of individual elements or their radioactive tracers. After 20 hours of equilibration at a given temperature an aliquot of the solution was withdrawn and analysed by ICP-MS or $\gamma$-ray spectrometry. The distribution coefficients were calculated from the formula:

$$
\lambda=\frac{A_{0}-A_{s}}{A_{s}} \cdot \frac{V}{m_{j}}
$$

where: $A_{0}$ - initial concentration (or count rate) of the standard solution, $A_{s}$ - concentration (or count rate) after equilibration, $V$-volume of the solution [mL], $m_{j}$ - mass of the dry ion exchange resin $[\mathrm{g}]$.

\section{Column experiments}

Glass and jacketed glass columns with an internal diameter (ID) of 3-6 mm were employed in column experiments. The resin bed of desired length was supported on a quartz wool plug. The solution of appropriate composition was passed through the column at a flow rate of $0.5-1.5 \mathrm{~cm} \cdot \mathrm{min}^{-1} \mathrm{using}$ a Pharmacia LKB P-1 peristaltic pump. An ultra thermostat (Julabo Labortechnik $\mathrm{GmbH}$ ) was used to maintain the desired temperature. The effluent was collected in fractions of established volume in test tubes by an FC 203B fraction collector (Gilson Medical Electronics, Inc.). The fractions were monitored by $\gamma$-ray spectrometry when radioactive tracers were used as well as by ICP-MS when non-radioactive elements were involved. 
Table 1. Parameters of the digestion process

\begin{tabular}{lccr}
\hline \multicolumn{1}{c}{ Operating conditions } & $\begin{array}{c}\text { Digestion program } \\
\text { (geological and environmental } \\
\text { materials) }\end{array}$ & $\begin{array}{c}\text { Digestion program } \\
\text { (biological materials) }\end{array}$ & $\begin{array}{c}\text { Removal of fluoride ions } \\
\text { program }\end{array}$ \\
\hline Power $[\mathrm{W}]$ & 1400 & 1400 & 600 \\
Pressure [bar] & 60 & 50 & 50 \\
Temperature $\left[{ }^{\circ} \mathrm{C}\right]$ & 220 & 210 & 190 \\
Time [min] & 60 & 45 & 45 \\
\hline
\end{tabular}

\section{Microwave-assisted total digestion}

Known amounts (maximum weight ca. $250 \mathrm{mg}$ ) of NCS DC73316 Chinese Stream Sediment were weighed into special Teflon vessels. Then $6 \mathrm{~mL}$ of concentrated $\mathrm{HNO}_{3}$ and $2 \mathrm{~mL}$ of $40 \% \mathrm{HF}$ were added. When decomposition was completed, $12 \mathrm{~mL}$ portions of $4 \% \mathrm{H}_{3} \mathrm{BO}_{3}$ solution were introduced to the samples and the vessels were re-sealed. The same sample size of Tea Leaves (INCT-TL-1) was digested by means of $6 \mathrm{~mL}$ of concentrated $\mathrm{HNO}_{3}, 2 \mathrm{~mL}$ of $30 \% \mathrm{H}_{2} \mathrm{O}_{2}$ and $0.5 \mathrm{~mL}$ of $40 \% \mathrm{HF}$. After digestion, $6 \mathrm{~mL}$ portions of $4 \% \mathrm{H}_{3} \mathrm{BO}_{3}$ solution were added to the samples and the vessels were re-sealed.

Digestion of the CRMs and removal of fluoride ions was carried out by applying the Multiwave 3000 high-pressure microwave system (Anton Paar GmbH) under controlled conditions. Programs used in this work are given in Table 1 . The resulting solutions were transferred into $50 \mathrm{~mL}$ PFA volumetric flasks.

\section{Gamma-ray spectrometric measurements and neutron activation analysis}

Gamma-ray spectrometric measurements of eluted fractions were performed by the Genie 2000 Gamma Spectroscopy System (Canberra Industries) with an HPGe (high-purity germanium) well-type detector (Canberra Industries). Its active volume was $255 \mathrm{~cm}^{3}$, relative efficiency $55 \%$, well depth $40 \mathrm{~mm}$ and well diameter $16 \mathrm{~mm}$. The average energy resolution amounted to $2.1 \mathrm{keV}$ for the $1332 \mathrm{keV}$ peak of ${ }^{60} \mathrm{Co}$.

Neutron activation analysis (NAA) was employed for the determination of rare earth elements in Tea Leaves (INCT-TL-1) and NCS DC73316 Chinese Stream Sediment both in solid samples and in samples from which the analytes were isolated while performing the elaborated separation schemes. In the first case, ca. $100 \mathrm{mg}$ of the material was weighed into a polyethylene (PE) capsule (Type "V", Vrije Universiteit, Biologisch Laboratorium, The Netherlands) and sealed. Isolated fractions of REEs were concentrated down to a small volume $(500 \mu \mathrm{L})$ and quantitatively transferred to PE capsules. The REE standards were prepared by weighing aliquots of standard solutions in PE capsules and evaporating to dryness before encapsulation. The irradiation package consisted of samples, standards and an empty capsule (blank) wrapped together in aluminium foil. Neutron activation was performed in the Maria nuclear reactor (Świerk, Po-

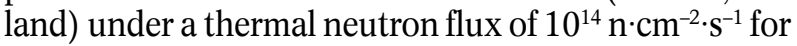
$50 \mathrm{~min}$. The cooling time was optimized and depended on the half-life of the elements of interest. Measurements were performed in two series, with respect to the half-life of particular radionuclides: La-140, Sm-153, Lu-177 and $\mathrm{Yb}-175$ required 2 to 7 days of cooling while Ce-141, Nd-147, Sc-46, Tb-160, Yb-169, Tm-170 and Eu-152 required 4 weeks of cooling.

\section{ICP-MS measurements}

The ELAN DRC II inductively coupled plasma quadrupole mass spectrometer (PerkinElmer) equipped with a cross flow nebulizer, a Scott double-pass spray chamber and Ni cones was employed for ICP-MS measurements. According to the manufacturer's recommendations, daily performance checks were always executed before series of analyses commenced. The aims were to control and optimize the instrument performance resulting in possible maximal intensities of $\mathrm{In}^{+}, \mathrm{Mg}^{+}, \mathrm{U}^{+}$and $\mathrm{Th}^{+}$ions. Moreover, the formation of oxides and doubly charged ions was examined by measuring the ratios $\mathrm{CeO}^{+} / \mathrm{Ce}^{+}$and $\mathrm{Ba}^{2+} / \mathrm{Ba}^{+}$, respectively. Both ratios did not exceed 3\%. The parameters for ICP-MS measurements were as follows:

- radio frequency $(\mathrm{RF})$ power: $1000 \mathrm{~W}$,

- nebulizer gas flow rate: $1.05 \mathrm{~L} \cdot \mathrm{min}^{-1}$,

- plasma gas flow rate: $15 \mathrm{~L} \cdot \mathrm{min}^{-1}$,

- auxiliary gas flow rate: $1.2 \mathrm{~L} \cdot \mathrm{min}^{-1}$,

- lens voltage: $5.75 \mathrm{~V}$,

- detector mode: dual,

- sample uptake rate: $20 \mathrm{rpm}$.

The ICP-MS measurements were based on the following isotopes: ${ }^{139} \mathrm{La},{ }^{140} \mathrm{Ce},{ }^{141} \mathrm{Pr},{ }^{142,144} \mathrm{Nd}$, ${ }^{152,154} \mathrm{Sm},{ }^{151,153} \mathrm{Eu},{ }^{157,158,160} \mathrm{Gd},{ }^{159} \mathrm{~Tb},{ }^{162,164} \mathrm{Dy},{ }^{165} \mathrm{Ho}$, ${ }^{166,168} \mathrm{Er},{ }^{169} \mathrm{Tm},{ }^{172,174} \mathrm{Yb},{ }^{175} \mathrm{Lu},{ }^{89} \mathrm{Y}$ and ${ }^{45} \mathrm{Sc}$. Indium was applied as an internal standard of $5 \mathrm{ng} \cdot \mathrm{mL}^{-1}$ in concentration.

\section{IC-UV/VIS measurements}

The fraction of REEs obtained from the Separation Scheme 1 (in $1.5 \mathrm{~mL}$ of $0.125 \mathrm{M} \mathrm{HNO}_{3}$ ) was injected into the chromatographic column using a $530 \mu \mathrm{L}$ sample loop. The analyses of REE fractions separated from CRMs were performed by a Dionex 2000i/SP ion chromatograph (Dionex Corporation, 1228 Titan Way, Sunnyvale, CA, USA) equipped with a Dionex VDM-II UV-VIS variable wavelength detector and a gradient pump (Dionex AGP). The REE cations were separated using a Dionex IonPac CS3 analytical column equipped with an IonPac CG3 guard column and $\alpha$-HIBA as a complexing eluent. A combined linear gradient and isocratic elution mode as well as 
other conditions of the REE analysis (Arsenazo III as the post-column reagent: $\lambda=658 \mathrm{~nm}$ with flow rate $=0.7 \mathrm{~mL} \cdot \mathrm{min}^{-1}$, sample loop $=530 \mathrm{~mL}$ and column temperature $=70^{\circ} \mathrm{C}$ ) were used.

\section{Procedure I (Separation Scheme I)}

When elaborating ion exchange chromatographic separations, radioactive tracers were dissolved in $7 \mathrm{M}$ nitric acid. A mixture of tracers was evaporated three times to wet salts with $1.5 \mathrm{M}$ nitric acid and finally was dissolved in $1.5 \mathrm{~mL}$ of the same solution. Such prepared sample was transferred to the top of the column filled with Dowex 50WX8 ion-exchange resin. Previously the column was conditioned with $1.5 \mathrm{M}$ nitric acid at a temperature of $45^{\circ} \mathrm{C}$. The effluent was collected in $2 \mathrm{~mL}$ fractions and measured by $\gamma$-ray spectrometry. Alternatively, when non-radioactive elements were used, the fractions were analysed by ICP-MS.

The procedure that was adopted in the end for the determination of REEs in the wet-ashed INCT-TL-1 CRM was as follows: after mineralization of two $250 \mathrm{mg}$ samples they were combined and evaporated to wet salts, dissolved in $2 \mathrm{~mL}$ of concentrated $\mathrm{HNO}_{3}$ and evaporated to a small volume. Subsequently the sample was evaporated with $1 \mathrm{~mL}$ of $\mathrm{HNO}_{3}+$ $1 \mathrm{~mL}$ of $\mathrm{H}_{3} \mathrm{BO}_{3}$ to wet salts (removal of fluorides), dissolved in $1 \mathrm{~mL}$ of concentrated $\mathrm{HNO}_{3}$, evaporated nearly to dryness and similarly evaporated three times with $1.5 \mathrm{~mL}$ of $1.5 \mathrm{M} \mathrm{HNO}_{3}$. Finally, the sample was dissolved in $1.5 \mathrm{~mL}$ of $1.5 \mathrm{M} \mathrm{HNO}_{3}$ and introduced on the top of a $0.262 \mathrm{~cm}^{2} \times 7.6 \mathrm{~cm}$ Dowex 50WX8 $\left[\mathrm{H}^{+}\right]$column $\left(100-200\right.$ mesh) at $45^{\circ} \mathrm{C}$ at a flow rate of $0.33 \mathrm{~mL} \cdot \mathrm{min}^{-1}$. Alkali, alkaline earth and some other divalent elements were eluted with $65 \mathrm{~mL}$ of $1.5 \mathrm{M} \mathrm{HNO}_{3}$. REEs together with some other mostly tervalent and tetravalent elements were eluted with $55 \mathrm{~mL}$ of $3.3 \mathrm{M} \mathrm{HNO}_{3}$. The REE fraction was evaporated to wet salts, then dissolved in $8 \mathrm{M} \mathrm{HBr}$, evaporated to dryness followed by evaporation three times with $1.5 \mathrm{~mL}$ of $8 \mathrm{M} \mathrm{HBr}$. Finally, it was dissolved in $1.5 \mathrm{~mL}$ of $8 \mathrm{M} \mathrm{HBr}$ and transferred to the top of a $0.217 \mathrm{~cm}^{2} \times 5.0 \mathrm{~cm}$ Dowex $1 \mathrm{X} 4\left[\mathrm{Br}^{-}\right]$ column (100-200 mesh) at $25^{\circ} \mathrm{C}$ and a flow rate of $0.20 \mathrm{~mL} \cdot \mathrm{min}^{-1}$. The REE fraction was eluted with $35 \mathrm{~mL}$ of $8 \mathrm{M} \mathrm{HBr}$, evaporated to dryness, dissolved in $1 \mathrm{~mL}$ of concentrated $\mathrm{HNO}_{3}$ and evaporated three times with $0.125 \mathrm{M} \mathrm{HNO}_{3}$. After dissolution in $1.5 \mathrm{~mL}$ of $0.125 \mathrm{M} \mathrm{HNO}_{3}$ the sample was analysed by ICP-MS and/or IC methods.

\section{Procedure 2 (Separation Scheme 2)}

During radioactive tracer experiments aimed at establishing optimum conditions for the quantitative isolation of rare earth elements, a small volume (50-100 $\mu \mathrm{L})$ of a solution containing radioactive tracers of $\mathrm{La}, \mathrm{Ce}, \mathrm{Nd}, \mathrm{Sm}, \mathrm{Eu}, \mathrm{Tb}, \mathrm{Tm}, \mathrm{Yb}$, Lu and Sc was introduced onto the top of the column. Then, the solution of appropriate composition was passed through the column with a flow rate of $0.5-1.5 \mathrm{~cm} \cdot \mathrm{min}^{-1}$ at room or established elevated temperatures. An ultra thermostat was used to maintain the desired temperature. The effluent was collected in test tubes as fractions of equal volume, using a fraction collector. The following procedure was finally applied to separate REEs from other accompanying elements present in the analysed materials. The digested sample was evaporated to dryness, dissolved in ca. $3 \mathrm{~mL}$ of $1 \mathrm{M} \mathrm{HNO}_{3}$ and introduced onto the top of the $\mathrm{Pu}$ rolite S-950 column $\left(0.127 \mathrm{~cm}^{2} \times 9.5 \mathrm{~cm}\right.$, particle size $50-100 \mu \mathrm{m})$, which was previously equilibrated with a large excess of $1 \mathrm{M} \mathrm{HNO}_{3}$. The solution of the sample contained less than 500 and $80 \mathrm{mg}$ of material of biological and geological or environmental origin, respectively. The bed was subsequently washed with $10 \mathrm{~mL}$ of $1 \mathrm{M} \mathrm{HNO}_{3}$ at room temperature, $50 \mathrm{~mL}$ of $1 \mathrm{M}$ citric acid $+1 \mathrm{M} \mathrm{NH}_{4} \mathrm{NO}_{3}+1.8 \mathrm{M} \mathrm{NH}_{3}$ at $t=$ $60^{\circ} \mathrm{C}$ and $30 \mathrm{~mL}$ of $0.5 \mathrm{M}$ nitrilotriacetic acid (NTA) $+1 \mathrm{M} \mathrm{NH}_{4} \mathrm{NO}_{3}+1.6 \mathrm{M} \mathrm{NH}_{3}$ at $t=60^{\circ} \mathrm{C}$. The last fraction (containing isolated REEs) was evaporated gently to wet salts in a quartz beaker, avoiding overheating. In order to mineralize NTA, the residue was dissolved in $10 \mathrm{~mL}$ of concentrated $\mathrm{HNO}_{3}$ and the sample was subsequently heated. At the beginning, portions of several drops of $30 \% \mathrm{H}_{2} \mathrm{O}_{2}$ (altogether $2 \mathrm{~mL}$ ) were carefully added. The solution was concentrated to a small volume and treated with $2 \mathrm{~mL}$ portions of concentrated $\mathrm{HCl}$ (to convert nitrates into chlorides) until the nitrogen oxides disappeared. The next step was evaporation nearly to dryness and dissolution in $3 \mathrm{~mL}$ of $0.5 \mathrm{M} \mathrm{HCl}$. Then, the sample was introduced onto the top of the Dowex 50WX8 $\left[\mathrm{H}^{+}\right]$column $0.384 \mathrm{~cm}^{2} \times 9.5 \mathrm{~cm}, 200-400$ mesh. The bed was washed with $50 \mathrm{~mL}$ of $0.5 \mathrm{M} \mathrm{HCl}$ to remove ammonium chloride and other impurities that resulted from carrying out the above separation procedure. A fraction containing rare earth elements was obtained by elution with the aid of $30 \mathrm{~mL}$ of $5 \mathrm{M} \mathrm{HNO}_{3}$. Finally, it was concentrated, transferred quantitatively into a $15 \mathrm{~mL}$ PE centrifuge tube, adjusted to the desired volume and weighed.

\section{Results and discussion}

\section{Separation Scheme I}

The scheme was devised by taking into account the general rules governing the selectivity of ion exchange reactions [13], our previous experience in the domain of REE separation $[14,15]$ and some optimizing column experiments. The separation of REEs from thorium by elution from sulphonic acid resins with strong mineral acids is difficult but according to the literature [16] may be enhanced at elevated temperatures. Weight distribution coefficients of $\mathrm{La}, \mathrm{Sm}, \mathrm{Lu}, \mathrm{Sc}$ as well as $\mathrm{Hf}$ and Th in the systems Dowex 50WX8 $\left[\mathrm{H}^{+}\right]-\mathrm{HCl}$ and Dowex 50WX8 $\left[\mathrm{H}^{+}\right]-\mathrm{HNO}_{3}$ were measured by batch equilibration with the use of ICP-MS. Their values as a function of acid concentration and of temperature are shown in Tables 2 and 3, respectively.

From the weight distribution coefficients determined by batch equilibration (see Tables 2 and 3), 

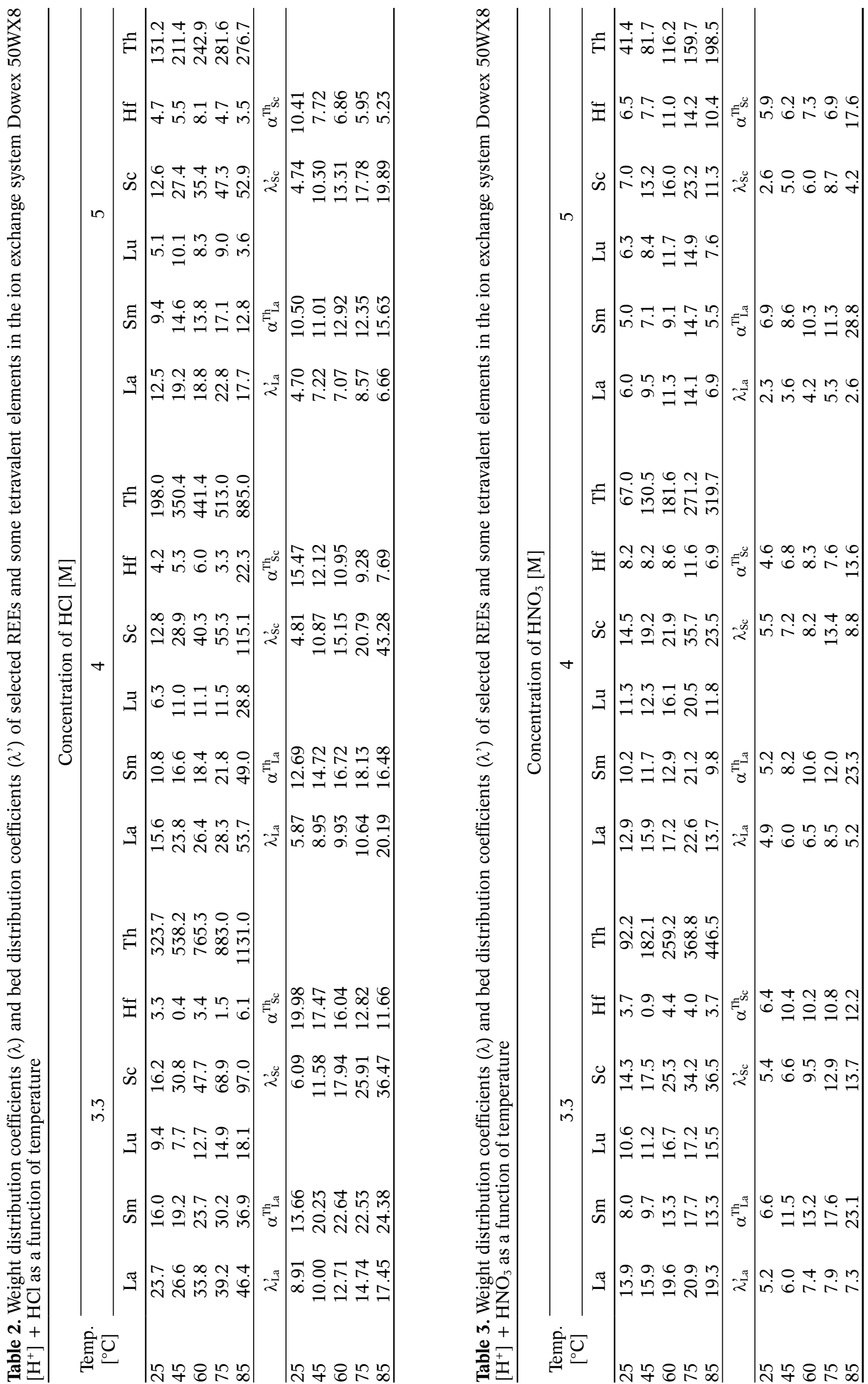


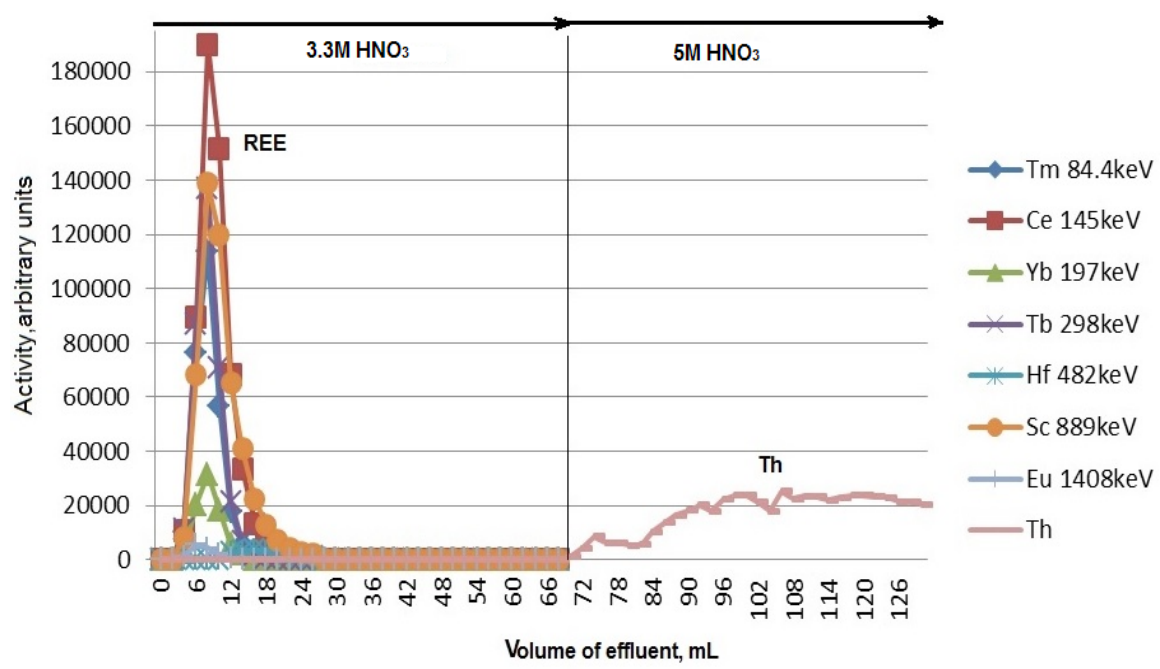

Fig. 1. Separation of REEs from thorium. Column: Dowex 50WX8 $\left[\mathrm{H}^{+}\right] 5 \mathrm{~cm} \times 0.262 \mathrm{~cm}^{2}(100-200 \mathrm{mesh})$, temperature $45^{\circ} \mathrm{C}$ for $3.3 \mathrm{M} \mathrm{HNO}_{3}, 60^{\circ} \mathrm{C}$ for $5 \mathrm{M} \mathrm{HNO}_{3}$; linear flow rate: $1.3 \mathrm{~cm} \cdot \mathrm{min}^{-1}$.

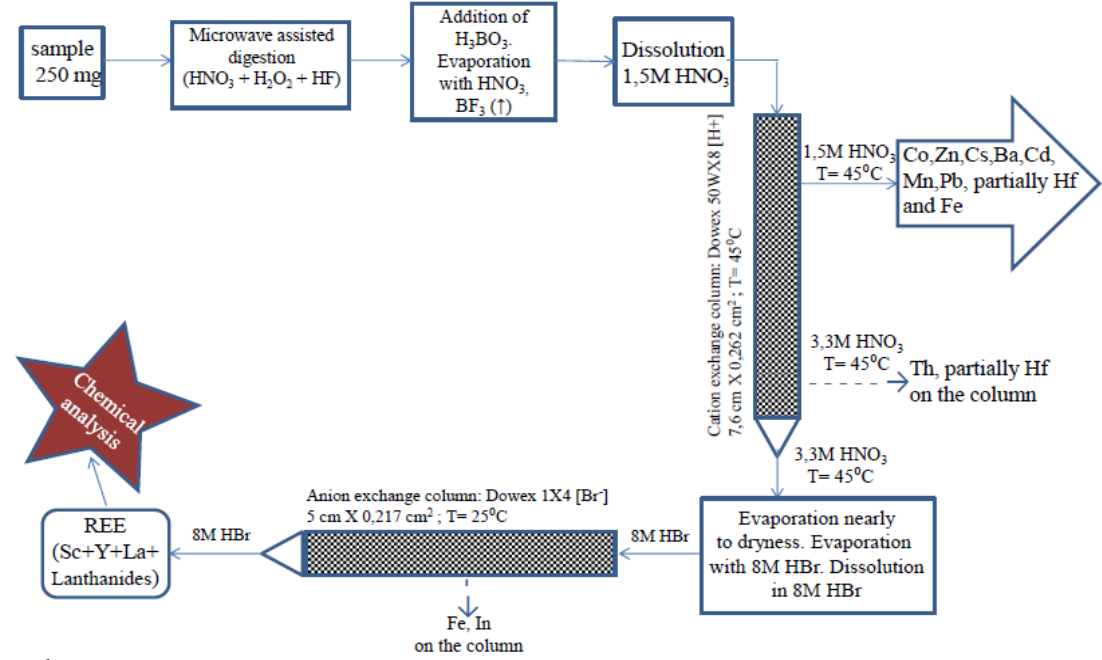

Fig. 2. Separation Scheme 1.

corresponding bed distribution coefficients, $\lambda$, were calculated from the equation:

$$
\lambda^{\prime}=\lambda \cdot d_{z}
$$

where $d_{z}$ is bed density (here $d_{z}=0.376 \mathrm{~g}$ of the dry ion exchanger per $\mathrm{mL}$ of the swollen resin bed), and $\lambda$ ' stands for the approximate peak elution volume of a given element expressed in column bed volumes [13].

In addition, separation factors of thorium with respect to lanthanum and scandium, respectively, in the investigated systems were obtained from the equations:

$$
\begin{aligned}
& \alpha_{\mathrm{La}}^{\mathrm{Th}}=\frac{\lambda_{\text {Th }}}{\lambda_{\mathrm{La}}}=\frac{\lambda_{\text {Th }}^{\prime}}{\lambda_{\mathrm{La}}^{\prime}} \\
& \alpha_{\mathrm{Sc}}^{\mathrm{Th}}=\frac{\lambda_{\text {Th }}}{\lambda_{\mathrm{Sc}}}=\frac{\lambda_{\text {Th }}^{\prime}}{\lambda_{\mathrm{Sc}}^{\prime}}
\end{aligned}
$$

Calculated values of bed distribution coefficients and separation factors are also included in Tables 2 and 3.

As follows from these data, the optimum conditions for the separation of Th from the REE group were a medium of $3.3 \mathrm{M} \mathrm{HNO}_{3}$ at $45^{\circ} \mathrm{C}$ and this was fully confirmed in the elution experiments (see Fig. 1). However, other tetravalent elements, e.g. Hf behaved in this system more like a REE than Th.

The whole of Separation Scheme 1, as shown in Fig. 2, also involved elimination of most of the uni- and divalent elements by elution from the Dowex 50WX8 $\left[\mathrm{H}^{+}\right]$column with $1.5 \mathrm{M} \mathrm{HNO}_{3}$ at $45^{\circ} \mathrm{C}$ (see Fig. 3a) followed by elution of REEs with $3.3 \mathrm{M} \mathrm{HNO}_{3}$ at $45^{\circ} \mathrm{C}$, while leaving thorium in the column. The REE fraction was further purified from other trivalent elements by rapid elution with $8 \mathrm{M} \mathrm{HBr}$ using the Dowex 1X4 [Br-] column which retained elements forming relatively strong bromide complexes (Fe, In, Ga, etc. - see Fig. 3b).

A dozen or so 150-200 mg samples of INCT-TL-1 Tea Leaves were digested and dissolved as described in the Experimental section, separated using Separation Scheme 1 and the rare earth fraction analysed by ICP-MS. The individual results were processed by a procedure devised earlier by a member of our research group [17] and the final outcome is presented in Table 4. As can be seen, the results are in good agreement with the certified values or "tentative recommended values" (TRV) [18]. 


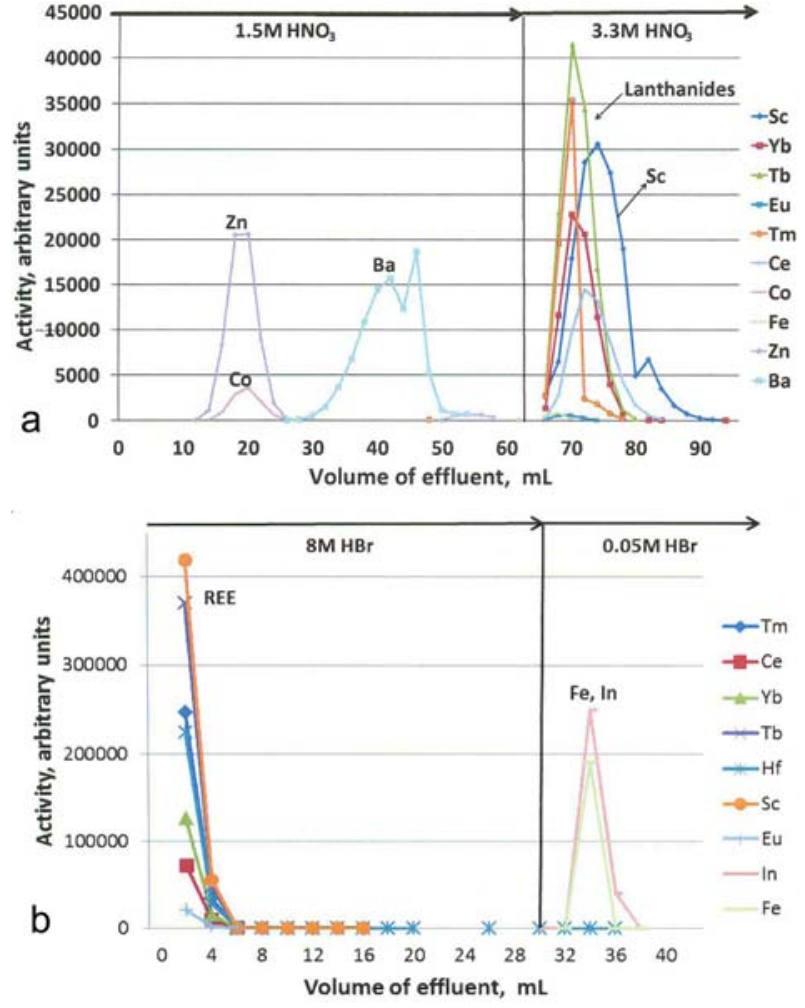

Fig. 3. Separation of REEs from accompanying elements. (a) Column: Dowex 50WX8 $\left[\mathrm{H}^{+}\right] 7.6 \mathrm{~cm} \times 0.262 \mathrm{~cm}^{2}(100-200$ mesh), temperature $45^{\circ} \mathrm{C}$, linear flow rate: $1.3 \mathrm{~cm} \cdot \mathrm{min}^{-1}$, eluent $1.5 \mathrm{M} \mathrm{HNO}_{3}$ : alkali and alkaline earth and some other divalent metals, eluent $3.3 \mathrm{M} \mathrm{HNO}_{3}$ : REEs and some other tri- and tetravalent elements. (b) Column: Dowex 1X4 [Br- $]$ $5.0 \mathrm{~cm} \times 0.217 \mathrm{~cm}^{2}(100-200 \mathrm{mesh})$, temperature $25^{\circ} \mathrm{C}$, linear flow rate: $0.92 \mathrm{~cm} \cdot \mathrm{min}^{-1}$, eluent $8 \mathrm{M} \mathrm{HBr}$ : REE fraction.

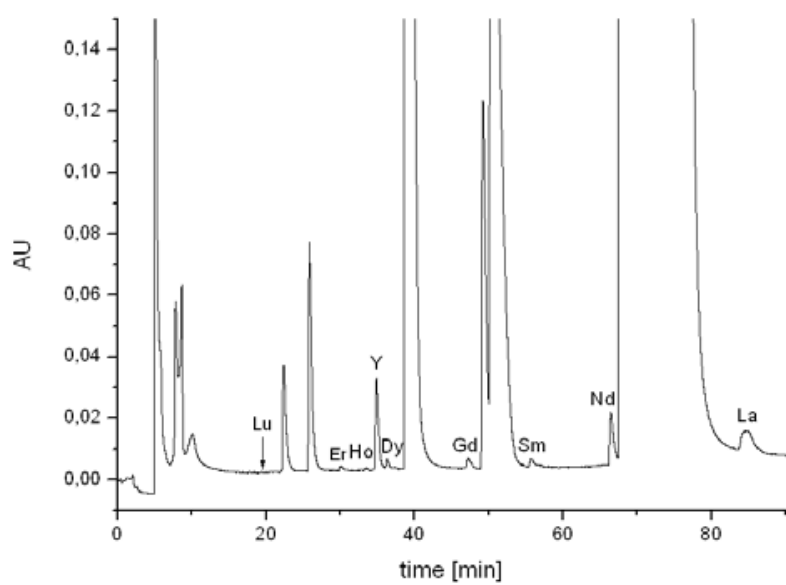

Fig. 4. Elution curve for REE cations obtained during combined isocratic and gradient elution chromatography. Column: Dionex IonPac CS3 + CG3. Eluent: 0-13 $\mathrm{min} ; 56 \mathrm{mmol} \cdot \mathrm{L}^{-1} \alpha-\mathrm{HIBA}$, then linear gradient 56-160 $\mathrm{mmol} \cdot \mathrm{L}^{-1} \alpha$-HIBA (up to $60 \mathrm{~min}$ ), next linear gradient $160-300 \mathrm{mmol} \cdot \mathrm{L}^{-1} \alpha$-HIBA (up to $85 \mathrm{~min}$ ), finally $300 \mathrm{mmol} \cdot \mathrm{L}^{-1} \alpha$-HIBA. Flow rate: $1 \mathrm{~mL} \cdot \mathrm{min}^{-1}$. Sample loop: $530 \mu \mathrm{L}$. Sample: REE fraction isolated from $235 \mathrm{mg}$ of Tea Leaves (INCT-TL-1) CRM. Temperature $70^{\circ} \mathrm{C}$. Elution curve showed chromatographic peaks of 9 REE cations determined in the sample. Other peaks are from unknown impurities present in the REE fraction.
Separation Scheme 1 was also used together with ion exchange chromatography $[19,20]$ and exemplary results from single runs are shown in Table 4 and Fig. 4. While this approach might look attractive, impurities that remained in the REE fraction interfered with the determination of some lanthanides and Sc, the results for deviating from accurate ones might occur for individual lanthanides, and in general the reproducibility of results was not satisfac-

Table 4. Results of REE determination in INCT-TL-1 by ICP-MS and IC after their group isolation performed by Separation Scheme 1

\begin{tabular}{|c|c|c|c|}
\hline Element & $\begin{array}{c}\text { Analytical } \\
\text { results* } \\
\text { by ICP-MS }\end{array}$ & $\begin{array}{l}\text { Analytical } \\
\text { results } \\
\text { by IC }\end{array}$ & $\begin{array}{l}\text { Certified } \\
\text { or TRV } \\
\text { value }\end{array}$ \\
\hline & \multicolumn{3}{|c|}{ Unit $\left[\mathrm{mg} \cdot \mathrm{kg}^{-1}\right][\mathrm{ppb}]$} \\
\hline $\mathrm{Sc}$ & $\begin{array}{l}254 \pm 57 \\
\quad(13)\end{array}$ & - & $266 \pm 24$ \\
\hline Y & $\begin{array}{c}1031 \pm 44 \\
(12)\end{array}$ & $\begin{array}{r}1150 \\
662\end{array}$ & - \\
\hline $\mathrm{La}$ & $\begin{array}{c}1042 \pm 105 \\
(14)\end{array}$ & 980 & $1000 \pm 70$ \\
\hline $\mathrm{Ce}$ & $\begin{array}{c}888 \pm 75 \\
(13)\end{array}$ & - & $790 \pm 76$ \\
\hline $\operatorname{Pr}$ & $\begin{array}{c}213 \pm 15 \\
(14)\end{array}$ & - & $196 \pm 64$ \\
\hline $\mathrm{Nd}$ & $\begin{array}{c}830 \pm 59 \\
(14)\end{array}$ & $\begin{array}{l}728 \\
363\end{array}$ & $779 \pm 152$ \\
\hline $\mathrm{Sm}$ & $\begin{array}{c}172 \pm 11 \\
(14)\end{array}$ & $\begin{array}{r}172 \\
92\end{array}$ & $177 \pm 22$ \\
\hline $\mathrm{Eu}$ & $\begin{array}{c}49.6 \pm 1.0 \\
(11)\end{array}$ & 51 & $49.4 \pm 9.4$ \\
\hline Gd & $\begin{array}{c}192 \pm 14 \\
(13)\end{array}$ & $\begin{array}{r}185 \\
68\end{array}$ & $182 \pm 48$ \\
\hline $\mathrm{Tb}$ & $\begin{array}{c}28.7 \pm 4.7 \\
(14)\end{array}$ & $\begin{array}{l}34 \\
27\end{array}$ & $26.5 \pm 2.4$ \\
\hline Dy & $\begin{array}{c}163 \pm 12 \\
(13)\end{array}$ & $\begin{array}{r}120 \\
62\end{array}$ & $155 \pm 18$ \\
\hline Ho & $\begin{array}{c}34.1 \pm 2.7 \\
(14)\end{array}$ & $\begin{array}{l}18 \\
21\end{array}$ & $25.6 \pm 6.2$ \\
\hline $\mathrm{Er}$ & $\begin{array}{c}99 \pm 4 \\
(12)\end{array}$ & $\begin{array}{l}60 \\
59\end{array}$ & $79.6 \pm 19.6$ \\
\hline $\mathrm{Tm}$ & $\begin{array}{c}15.1 \pm 1.4 \\
(14)\end{array}$ & 18 & $14.0 \pm 5.9$ \\
\hline $\mathrm{Yb}$ & $\begin{array}{c}106 \pm 4 \\
(11)\end{array}$ & 64 & $118 \pm 13$ \\
\hline $\mathrm{Lu}$ & $\begin{array}{c}16.8 \pm 1.4 \\
(14)\end{array}$ & $\begin{array}{l}17 \\
18\end{array}$ & $16.8 \pm 2.4$ \\
\hline
\end{tabular}

* Results are presented as: $\bar{x} \pm t_{0.05} s n^{-1 / 2}(n)$, where $\bar{x}$-arithmetic mean, $t_{0.05}$ - parameter of $t$ - Student's distribution for significance level $\alpha=0.05$ and $n-1$ degrees of freedom, $n$ - number of determinations.

The number of determinations is given in the parenthesis. TRV values are shown in italics. 
tory. Because of these problems and the fact that only a limited number of lanthanides could be quantified, this aspect of the investigation was not pursued.

\section{Separation Scheme 2}

Our earlier experience in the field of ion exchange chromatography indicates that amphoteric ion exchange resins [21-27] might be potentially useful for the selective isolation of rare earth elements. Resins of this type contain functional groups, which can retain both cations and anions depending on the composition of the external solution. This feature can be differentiated from conventional monofunctional ion exchange resins that possess either cationic or anionic exchange sites.

Numerous column experiments were carried out to identify an ion exchange system suitable for the isolation of REEs. As the stationary phase, three amphoteric resins were examined, namely Retardion $11 \mathrm{~A} 8$ containing quaternary ammonium groups and an equivalent of carboxylate groups, Chelex 100 with iminodiacetic acid groups, and Purolite S950 with aminophosphonic acid groups. The mobile phase was a solution, with a constant $\mathrm{pH}$, composed of neutral salts $\left(\mathrm{NaNO}_{3}\right.$ or $\left.\mathrm{NH}_{4} \mathrm{NO}_{3}\right)$ and sodium or

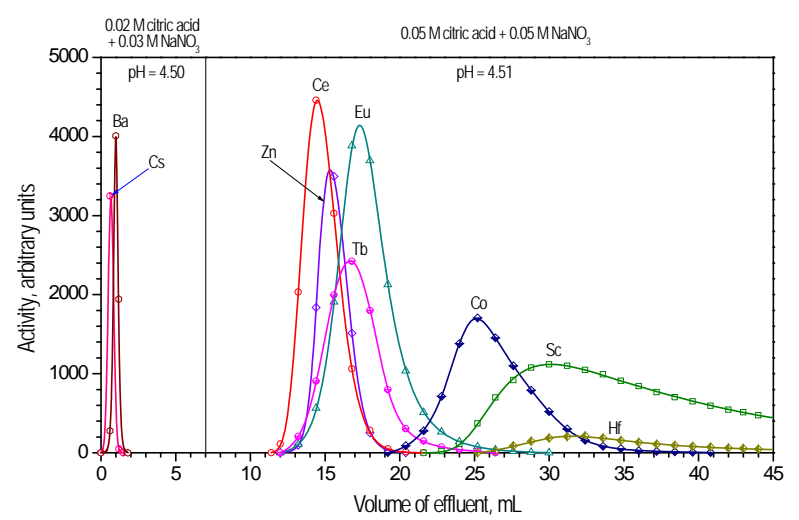

Fig. 5. Elution behaviour of REEs and other elements while passing citric acid solutions through the column filled with Retardion 11A8 ion exchange resin. Column: $8.5 \mathrm{~cm} \times$ $0.0707 \mathrm{~cm}^{2}$; Retardion 11A8 $(49-92 \mu \mathrm{m})$; temperature $25^{\circ} \mathrm{C}$, linear flow rate: $1.3 \mathrm{~cm} \cdot \mathrm{min}^{-1}$.

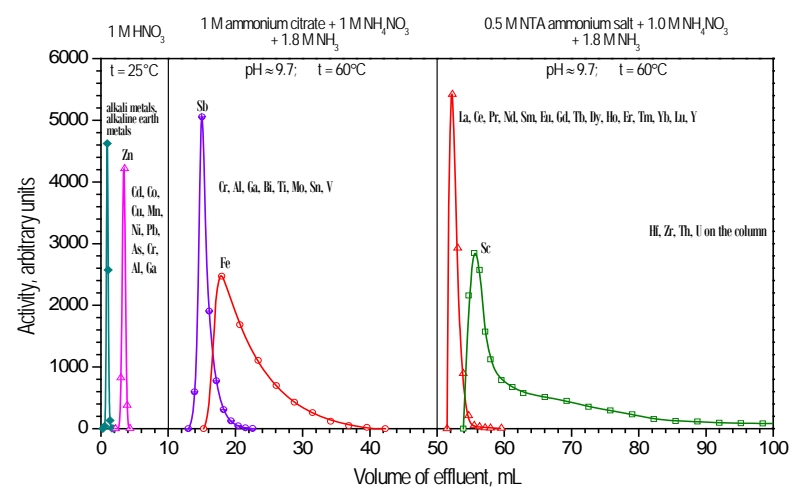

Fig. 6. Separation of REEs from accompanying elements by a stepwise elution at established temperatures using Purolite S950 ion exchange resin. Column: $8.5 \mathrm{~cm} \times$ $0.0707 \mathrm{~cm}^{2}$; Purolite S950 $(50-100 \mu \mathrm{m})$, linear flow rate: $1.1 \mathrm{~cm} \cdot \mathrm{min}^{-1}$. ammonium salts of the following complexing organic acids: citric (CA), tartaric (TA), diethylenetriaminepentaacetic (DTPA) and nitrilotriacetic (NTA). As is known, the temperature may be in some cases a critical parameter to achieve effective separation of elements of interest from others by ion exchange chromatography. Therefore, a series of elutions was performed not only at room temperature but also at elevated temperatures. Attempts to use ion exchange resins like Retardion 11A8 and Chelex 100 for REE isolation turned out to be unsuccessful, despite applying various combinations of $\mathrm{pH}$ and composition of the eluent as well as temperature of the process. A typical result of these investigations is the elution presented in Fig. 5. As can be seen, alkali and alkaline earth metals can be rapidly eluted at the beginning. Unfortunately, a number of elements exhibit similar ion exchange behaviour, as lanthanides and scandium. Thus, their separation as an individual fraction is impossible.

This aim was finally fulfilled by exploiting the third ion exchange resin, i.e. Purolite S950, which retains many metals in the form of chelates with aminophosphonic acid groups. As a result of many experiments, the chromatographic procedure based on a stepwise elution was elaborated (Fig. 6). Traces of REEs together with accompanying elements in a solution of $1 \mathrm{M} \mathrm{HNO}_{3}$ were introduced onto the column filled with Purolite S950. The first step was elution with $1 \mathrm{M} \mathrm{HNO}_{3}$ at room temperature. Monovalent and divalent elements (alkali metals, alkaline earth metals, $\mathrm{Cu}, \mathrm{Mn}, \mathrm{Zn}, \mathrm{Cd}, \mathrm{Ni}, \mathrm{Pb}$, $\mathrm{Co}$, etc.) and the part of the $\mathrm{Cr}, \mathrm{Al}$, Ga were removed from the column. The next step was to rinse with a solution of the composition: $1 \mathrm{M}$ ammonium citrate $+1 \mathrm{M} \mathrm{NH}_{4} \mathrm{NO}_{3}+1.8 \mathrm{M} \mathrm{NH}_{3}(\mathrm{pH} \approx 9.7)$ at $t=60^{\circ} \mathrm{C}$. Together with the rest of the $\mathrm{Cr}, \mathrm{Al}$ and $\mathrm{Ga}$, metals such as $\mathrm{Sb}, \mathrm{Fe}, \mathrm{Ti}, \mathrm{Mo}, \mathrm{Bi}, \mathrm{Sn}$ and $\mathrm{V}$ that remained on the column while the previous stage was performed, were eluted. The elements of interest, i.e. lanthanides, yttrium and scandium, were finally removed by means of a solution of $0.5 \mathrm{M}$ NTA ammonium salt $+1 \mathrm{M}$ $\mathrm{NH}_{4} \mathrm{NO}_{3}+1.6 \mathrm{M} \mathrm{NH}_{3}(\mathrm{pH} \approx 9.6)$ at $t=60^{\circ} \mathrm{C}$. It is worth emphasizing that tetravalent metals, i.e. U, $\mathrm{Th}, \mathrm{Zr}$ and Hf, remain firmly bound to the resin. Desorption of Sc poses a problem because of a broad band with a long tail resulting in it failing to elute quantitatively in contrast to all other REEs. As was shown using radioactive tracers, traces of scandium were still observed in the column even after passing quite a large volume of the eluent through it. The probable cause of such behaviour seems to be poor kinetics of the reaction, where aminophosphonic acid groups of Purolite S950 (binding Sc in the stationary phase) are replaced by NTA anions and then the newly formed chelate is transferred to the mobile phase.

Separation Scheme 2 in its entirety, based on chromatographic isolation of REEs employing the Purolite S950 ion exchange resin, is shown in Fig. 7. Rather high concentrations of NTA and $\mathrm{NH}_{4} \mathrm{NO}_{3}$ in the final fraction were the reasons why the direct determination of the analytes by ICP-MS as well as NAA was impossible. Therefore, it was necessary to introduce additional steps to mineralize 


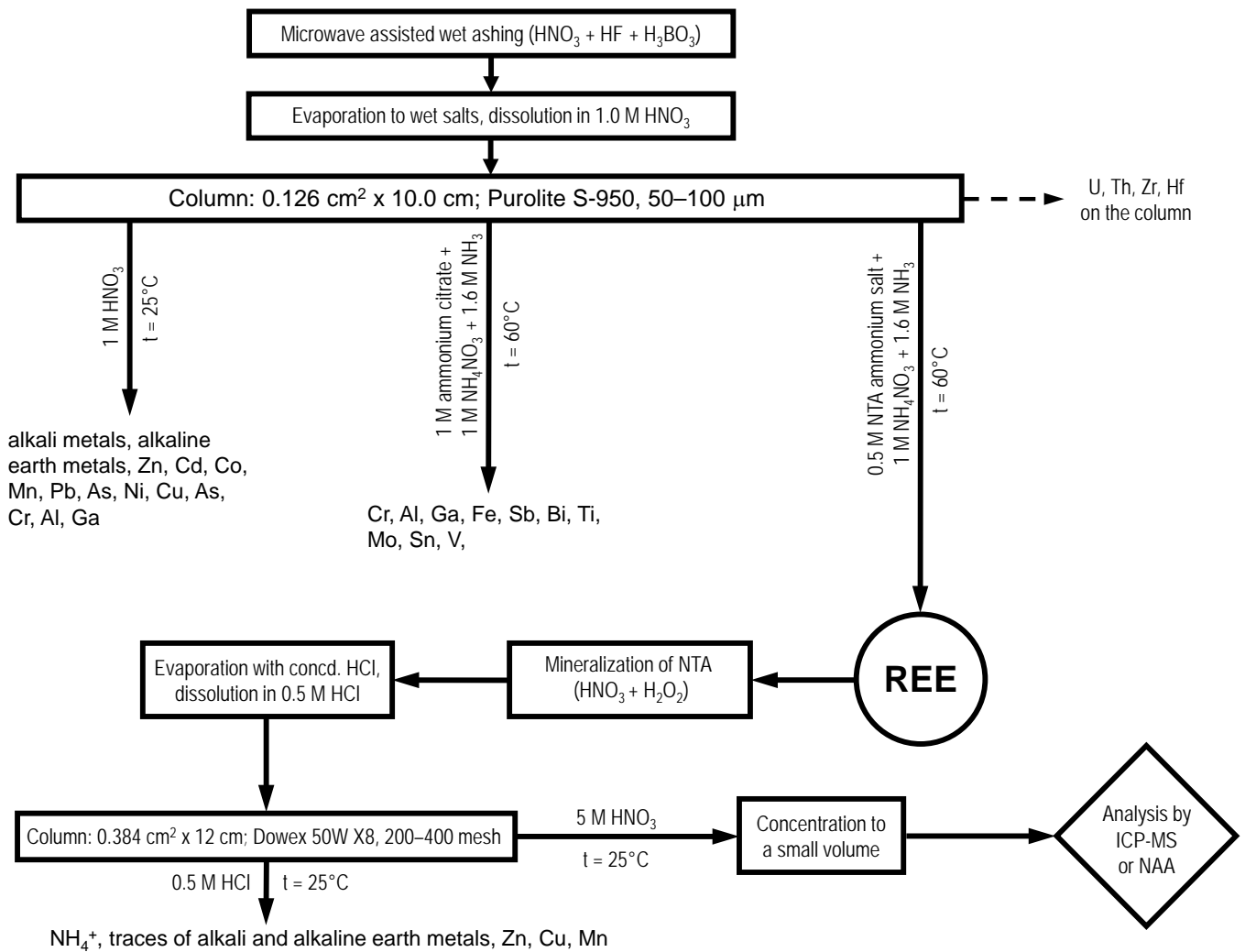

Fig. 7. Separation Scheme 2.

the NTA and then eliminate the ammonium salts. The latter purpose was rapidly and effectively realized when the strongly acidic cation exchange resin Dowex 50WX8 was used. Rinsing of the column with $0.5 \mathrm{M} \mathrm{HCl}$ resulted in the removal of $\mathrm{NH}_{4}^{+}$together with traces of other cations originating from the reagents applied while performing the previous separation stages. Rare earth elements are finally eluted by means of a solution of $5 \mathrm{M} \mathrm{NHO}_{3}$ and after being concentrated the effluent may be analysed using ICP-MS and NAA. Separation Scheme 2 assured good selectivity of REE isolation. The analysis of real samples by ICP-MS revealed that the presence of many other elements in the REE fraction did not exceed the level normally observed in the blank.

The results of REE determination in the CRM Tea Leaves (INCT-TL-1), with the aid of ICP-MS as well as NAA, obtained after performing Separation Scheme 2 are shown in Table 5. Analogous data for the other CRM, namely Chinese Stream Sediment (NCS DC73316) are listed in Table 6. As can be seen, the analytical results remain in good agreement and for some elements in the very good agreement with the certified values. An exception to the rule is scandium, for which the results are distinctly lower due to the above-mentioned reasons so its elution using Purolite S950 was incomplete.

\section{Direct measurements and their comparison with those employing REE pre-separation}

Results of direct measurements on solid and wet-ashed samples of INCT-TL-1 by INAA and ICP-MS, respectively, are shown in Table 7. Table 8 presents analogous results obtained for NCS DC73316.

In the case of biological materials (INCT-TL-1) the direct ICP-MS method yields correct results for most of the lanthanides ( $\mathrm{La}, \mathrm{Ce}, \mathrm{Pr}, \mathrm{Nd}, \mathrm{Sm}, \mathrm{Eu}$, Gd, Tb, Dy, Ho, Er, Tm and Lu - see Table 7). The criterion for accurate results was the overlapping of the confidence interval of the experimental results with the uncertainty range of the certified value or tentative recommended value (TRV) [18]. The result for $\mathrm{Yb},(99.3 \pm 5.3) \mathrm{ng}^{\mathrm{g}} \mathrm{g}^{-1}$, is too low in comparison with the certified value $(118 \pm 13) \mathrm{ng} \cdot \mathrm{g}^{-1}$. On the other hand, after pre-separation of the REE group with the aid of Separation Scheme 2 the results by ICP-MS (119 \pm 5$)$, and INAA (119 \pm 7$)$, cf. Table 5, agree well with the certified value. Good agreement with the certified value for $\mathrm{Yb}$ in INCT-TL-1 was confirmed also by INAA results $(131 \pm$ 10 - see Table 7) and ICP-MS after pre-separation by Separation Scheme $1(106 \pm 4-$ see Table 4$)$. The accuracy for yttrium could not be checked because neither the certified value nor the TRV for this element was available. However, there is fairly good agreement between results determined by direct ICP-MS measurements on digested INCT-TL-1 samples $(1075 \pm 56)$ and those obtained after using Separation Scheme $1(1031 \pm 44)$ and Separation Scheme $2(1010 \pm 32)$, respectively.

A completely erroneous result was obtained for scandium $(1173 \pm 391)$ when compared to its certified value $(266 \pm 24)$. Far too high results for Sc came as a surprise and the reasons for such are not that clear. According to some authors [28], digestion of organic samples with nitric acid at temperatures 
Table 5. Results of REE determination in INCT-TL-1 by ICP-MS and NAA after their group isolation performed by Separation Scheme 2

\begin{tabular}{|c|c|c|c|c|c|c|c|}
\hline \multirow[t]{2}{*}{ Element } & $\begin{array}{c}\text { Analytical } \\
\text { results* } \\
\text { by ICP-MS }\end{array}$ & $\begin{array}{l}\text { Analytical } \\
\text { results* } \\
\text { by NAA }\end{array}$ & $\begin{array}{l}\text { Certified } \\
\text { or TRV } \\
\text { value }\end{array}$ & \multirow[t]{2}{*}{ Element } & $\begin{array}{l}\text { Analytical } \\
\text { results* } \\
\text { by ICP-MS }\end{array}$ & $\begin{array}{l}\text { Analytical } \\
\text { results* } \\
\text { by NAA }\end{array}$ & $\begin{array}{l}\text { Certified } \\
\text { value }\end{array}$ \\
\hline & \multicolumn{3}{|c|}{ Unit $\left[\mathrm{ng} \cdot \mathrm{g}^{-1}\right][\mathrm{ppb}]$} & & \multicolumn{3}{|c|}{ Unit $\left[\mathrm{mg} \cdot \mathrm{kg}^{-1}\right][\mathrm{ppm}]$} \\
\hline $\mathrm{Sc}$ & $\begin{array}{c}146 \pm 75 \\
(6)\end{array}$ & - & $266 \pm 24$ & $\mathrm{Sc}$ & $\begin{array}{c}10.4 \pm 1.3 \\
(5)\end{array}$ & - & $17 \pm 2.0$ \\
\hline Y & $\begin{array}{c}1010 \pm 32 \\
(6)\end{array}$ & - & - & $\mathrm{Y}$ & $\begin{array}{c}20.0 \pm 0.2 \\
(5)\end{array}$ & - & $20 \pm 2$ \\
\hline $\mathrm{La}$ & $\begin{array}{c}1014 \pm 45 \\
(6)\end{array}$ & $\begin{array}{c}992 \pm 91 \\
(6)\end{array}$ & $1000 \pm 70$ & $\mathrm{La}$ & $\begin{array}{c}38 \pm 2 \\
(5)\end{array}$ & $\begin{array}{c}33 \pm 2 \\
(4)\end{array}$ & $39 \pm 6$ \\
\hline $\mathrm{Ce}$ & $\begin{array}{c}819 \pm 99 \\
(6)\end{array}$ & $\begin{array}{c}1085 \pm 284 \\
(6)\end{array}$ & $790 \pm 76$ & $\mathrm{Ce}$ & $\begin{array}{c}70 \pm 2 \\
(5)\end{array}$ & $\begin{array}{c}67 \pm 6 \\
(4)\end{array}$ & $68 \pm 7$ \\
\hline $\operatorname{Pr}$ & $\begin{array}{c}211 \pm 24 \\
(6)\end{array}$ & - & $196 \pm 64$ & $\operatorname{Pr}$ & $\begin{array}{c}8.3 \pm 0.5 \\
(5)\end{array}$ & - & $8.4 \pm 0.8$ \\
\hline $\mathrm{Nd}$ & $\begin{array}{c}816 \pm 86 \\
(6)\end{array}$ & $\begin{array}{c}667 \pm 180 \\
(6)\end{array}$ & $779 \pm 152$ & $\mathrm{Nd}$ & $\begin{array}{c}30 \pm 5 \\
(5)\end{array}$ & $\begin{array}{c}34 \pm 5 \\
(4)\end{array}$ & $33 \pm 6$ \\
\hline $\mathrm{Sm}$ & $\begin{array}{c}177 \pm 7 \\
(6)\end{array}$ & $\begin{array}{c}168 \pm 8 \\
(6)\end{array}$ & $177 \pm 22$ & $\mathrm{Sm}$ & $\begin{array}{c}5.6 \pm 0.1 \\
(5)\end{array}$ & $\begin{array}{c}5.4 \pm 0.5 \\
(4)\end{array}$ & $5.6 \pm 0.6$ \\
\hline $\mathrm{Eu}$ & $\begin{array}{c}49.4 \pm 1.4 \\
(6)\end{array}$ & $\begin{array}{c}54.1 \pm 6.3 \\
(6)\end{array}$ & $49.4 \pm 9.4$ & $\mathrm{Eu}$ & $1.51 \pm 0.03$ & $\begin{array}{c}1.63 \pm 0.11 \\
(4)\end{array}$ & $1.50 \pm 0.13$ \\
\hline $\mathrm{Gd}$ & $\begin{array}{c}196 \pm 9 \\
(6)\end{array}$ & - & $182 \pm 48$ & $\mathrm{Gd}$ & $\begin{array}{c}5.5 \pm 0.1 \\
(5)\end{array}$ & - & $5.5 \pm 0.9$ \\
\hline $\mathrm{Tb}$ & $\begin{array}{c}26.7 \pm 0.8 \\
(6)\end{array}$ & $\begin{array}{c}25.0 \pm 5.6 \\
(6)\end{array}$ & $26.5 \pm 2.4$ & $\mathrm{~Tb}$ & $\begin{array}{c}0.70 \pm 0.02 \\
(5)\end{array}$ & $\begin{array}{c}0.59 \pm 0.16 \\
(4)\end{array}$ & $0.69 \pm 0.17$ \\
\hline Dy & $\begin{array}{c}160 \pm 7 \\
(6)\end{array}$ & - & $155 \pm 18$ & Dy & $\begin{array}{c}3.8 \pm 0.1 \\
(5)\end{array}$ & - & $3.8 \pm 0.9$ \\
\hline Ho & $\begin{array}{c}33.8 \pm 3.2 \\
(6)\end{array}$ & - & $25.6 \pm 6.2$ & Ho & $\begin{array}{c}0.77 \pm 0.03 \\
(5)\end{array}$ & - & $0.76 \pm 0.10$ \\
\hline Er & $\begin{array}{c}96.4 \pm 5.4 \\
(6)\end{array}$ & - & $79.6 \pm 19.6$ & $\mathrm{Er}$ & $\begin{array}{c}2.2 \pm 0.1 \\
(5)\end{array}$ & - & $2.2 \pm 0.5$ \\
\hline $\mathrm{Tm}$ & $\begin{array}{c}15.6 \pm 1.4 \\
(6)\end{array}$ & $\begin{array}{c}19.2 \pm 5.7 \\
(6)\end{array}$ & $14.0 \pm 5.9$ & $\mathrm{Tm}$ & $\begin{array}{c}0.31 \pm 0.02 \\
(5)\end{array}$ & $\begin{array}{c}0.37 \pm 0.13 \\
(4)\end{array}$ & $0.35 \pm 0.06$ \\
\hline $\mathrm{Yb}$ & $\begin{array}{c}119 \pm 5 \\
(6)\end{array}$ & $\begin{array}{c}119 \pm 7 \\
(6)\end{array}$ & $118 \pm 13$ & $\mathrm{Yb}$ & $\begin{array}{c}2.0 \pm 0.1 \\
(5)\end{array}$ & $\begin{array}{c}2.5 \pm 0.5 \\
(4)\end{array}$ & $2.1 \pm 0.3$ \\
\hline $\mathrm{Lu}$ & $\begin{array}{c}17.9 \pm 1.8 \\
(6)\end{array}$ & $\begin{array}{c}16.4 \pm 3.4 \\
(6)\end{array}$ & $16.8 \pm 2.4$ & $\mathrm{Lu}$ & $\begin{array}{c}0.30 \pm 0.02 \\
(5)\end{array}$ & $\begin{array}{c}0.27 \pm 0.02 \\
(4)\end{array}$ & $0.34 \pm 0.09$ \\
\hline
\end{tabular}

* Results are presented as: $\bar{x} \pm t_{0.05} s n^{-1 / 2}(n)$, where $\bar{x}$-arithmetic mean, $t_{0.05}$ - parameter of $t$-Student's distribution for significance level $\alpha=0.05$ and $n-1$ degrees of freedom, $n$ - number of determinations.

The number of determinations is given in the parenthesis.

TRV values are shown in italics.

below $300^{\circ} \mathrm{C}$ may result in incomplete removal of organic carbon. This fact, together with the presence of residual $\mathrm{Si}$ in the solution, might lead to the formation of some molecular ions, e.g. ${ }^{12} \mathrm{C}^{16} \mathrm{O}_{2}{ }^{1} \mathrm{H}^{+}$, ${ }^{28} \mathrm{Si}^{16} \mathrm{O}^{1} \mathrm{H}^{+},{ }^{29} \mathrm{Si}^{16} \mathrm{O}^{+},{ }^{14} \mathrm{~N}_{2}{ }^{16} \mathrm{O}^{1} \mathrm{H}^{+}$and ${ }^{13} \mathrm{C}^{16} \mathrm{O}_{2}^{+}$, that could account for serious positive errors when determining the result for Sc by ICP-MS.

After pre-separation of the REE group from the matrix the result for scandium $(254 \pm 57$ - see
Table 6. Results of REE determination in NCS DC73316 by ICP-MS and NAA after their group isolation performed by Separation Scheme 2 "Results are presented as: $\bar{x} \pm t_{0.05} s n^{-1 / 2}(n)$, where $\bar{x}$-arithmetic
mean, $t_{0.05}$ - parameter of $t$-Student's distribution for significance level $\alpha=0.05$ and $n-1$ degrees of freedom, $n$ - number

The number of determinations is given in the parenthesis.

Table 4) agrees with its certified value, as does the result obtained by INAA ( $290 \pm 18$ - see Table 7$)$.

Because of the distance from the reactor and radiological safety precautions, only medium- and long-lived radioisotopes could be used in the INAA procedure employed in this study. As can be seen from Table 7, in the case of INCT-TL-1 all results for $\mathrm{Sc}, \mathrm{La}, \mathrm{Ce}, \mathrm{Nd}, \mathrm{Sm}, \mathrm{Eu}, \mathrm{Tb}, \mathrm{Tm}, \mathrm{Yb}$ and $\mathrm{Lu}$ are in good agreement with their certified values. of determinations. 
Table 7. Results of REE determination in INCT-TL-1 by ICP-MS (digested samples) and INAA (solid samples)

\begin{tabular}{|c|c|c|c|}
\hline \multirow[t]{2}{*}{ Element } & $\begin{array}{l}\text { Analytical } \\
\text { results* } \\
\text { by ICP-MS }\end{array}$ & $\begin{array}{l}\text { Analytical } \\
\text { results* } \\
\text { by INAA }\end{array}$ & $\begin{array}{c}\text { Certified } \\
\text { or TRV } \\
\text { value }\end{array}$ \\
\hline & \multicolumn{3}{|c|}{ Unit $\left[\mathrm{ng} \cdot \mathrm{g}^{-1}\right][\mathrm{ppb}]$} \\
\hline $\mathrm{Sc}$ & $\begin{array}{c}1173 \pm 391 \\
(7)\end{array}$ & $\begin{array}{c}290 \pm 18 \\
(4)\end{array}$ & $266 \pm 24$ \\
\hline $\mathrm{Y}$ & $\begin{array}{c}1075 \pm 56 \\
(7)\end{array}$ & - & - \\
\hline $\mathrm{La}$ & $\begin{array}{c}1005 \pm 38 \\
(7)\end{array}$ & $\begin{array}{c}1079 \pm 121 \\
(4)\end{array}$ & $1000 \pm 70$ \\
\hline $\mathrm{Ce}$ & $\begin{array}{c}715 \pm 19 \\
(7)\end{array}$ & $\begin{array}{c}775 \pm 39 \\
(4)\end{array}$ & $790 \pm 76$ \\
\hline $\operatorname{Pr}$ & $\begin{array}{c}199 \pm 7 \\
(7)\end{array}$ & - & $196 \pm 64$ \\
\hline $\mathrm{Nd}$ & $\begin{array}{c}780 \pm 22 \\
(7)\end{array}$ & $\begin{array}{c}689 \pm 17 \\
(4)\end{array}$ & $779 \pm 152$ \\
\hline $\mathrm{Sm}$ & $\begin{array}{c}169 \pm 5 \\
(7)\end{array}$ & $\begin{array}{c}176 \pm 23 \\
(4)\end{array}$ & $177 \pm 22$ \\
\hline $\mathrm{Eu}$ & $\begin{array}{c}50.9 \pm 1.9 \\
(7)\end{array}$ & $\begin{array}{c}49.6 \pm 0.9 \\
(4)\end{array}$ & $49.4 \pm 9.4$ \\
\hline $\mathrm{Gd}$ & $\begin{array}{c}193 \pm 5 \\
(7)\end{array}$ & - & $182 \pm 48$ \\
\hline $\mathrm{Tb}$ & $\begin{array}{c}27.6 \pm 2.5 \\
(7)\end{array}$ & $\begin{array}{c}24.9 \pm 0.9 \\
(4)\end{array}$ & $26.5 \pm 2.4$ \\
\hline Dy & $\begin{array}{c}156 \pm 10 \\
(7)\end{array}$ & - & $155 \pm 18$ \\
\hline Ho & $\begin{array}{c}31.0 \pm 1.5 \\
(7)\end{array}$ & - & $25.6 \pm 6.2$ \\
\hline Er & $\begin{array}{c}87.9 \pm 5.2 \\
\quad(7)\end{array}$ & - & $79.6 \pm 19.6$ \\
\hline $\mathrm{Tm}$ & $\begin{array}{c}13.7 \pm 1.2 \\
(7)\end{array}$ & $\begin{array}{c}17.8 \pm 0.7 \\
(4)\end{array}$ & $14.0 \pm 5.9$ \\
\hline $\mathrm{Yb}$ & $\begin{array}{c}99.3 \pm 5.3 \\
(7)\end{array}$ & $\begin{array}{c}131 \pm 10 \\
(4)\end{array}$ & $118 \pm 13$ \\
\hline $\mathrm{Lu}$ & $\begin{array}{c}16.5 \pm 0.2 \\
(7)\end{array}$ & $\begin{array}{c}18.7 \pm 0.9 \\
(4)\end{array}$ & $16.8 \pm 2.4$ \\
\hline $\begin{array}{l}\text { * Results are } \\
\text { mean, } t_{0.05}- \\
\text { cance level } \\
\text { of determine } \\
\text { The numb } \\
\text { TRV value }\end{array}$ & $\begin{array}{l}\text { esented as: } \bar{x} \pm \\
\text { rameter of } t- \\
0.05 \text { and } n- \\
\text { ns. } \\
\text { of determinati }\end{array}$ & $\begin{array}{l}\text { S } n^{-1 / 2}(n) \text { wh } \\
\text { udent's distrib } \\
\text { legrees of free } \\
\text { is given in the }\end{array}$ & $\begin{array}{l}\bar{x}-\text { arithmetic } \\
\text { ion for signifi- } \\
\text { m, } n \text { - number } \\
\text { arenthesis. }\end{array}$ \\
\hline
\end{tabular}

As for the geological CRM, NCS DC73316 see Table 8 , results were similar to that described above. Here the result for Y by ICP-MS, $(17.5 \pm 0.6)$ $\mathrm{mg} \cdot \mathrm{kg}^{-1}$, seems to be slightly too low when compared with its certified value $(20 \pm 2)$. The results after pre-separation of REEs by Separation Scheme 2 $(20.0 \pm 0.2-$ see Table 6$)$ are in perfect agreement with its certified value.

The result for Sc $(25.0 \pm 1.8)$ again falls outside the uncertainty range of its certified value (17.0 \pm
Table 8. Results of REE determination in NCS DC73316 by ICP-MS (digested samples) and INAA (solid samples)

\begin{tabular}{|c|c|c|c|}
\hline Element & $\begin{array}{l}\text { Analytical } \\
\text { results* } \\
\text { by ICP-MS }\end{array}$ & $\begin{array}{l}\text { Analytical } \\
\text { results* } \\
\text { by INAA }\end{array}$ & $\begin{array}{l}\text { Certified } \\
\text { value }\end{array}$ \\
\hline & \multicolumn{3}{|c|}{ Unit $\left[\mathrm{mg} \cdot \mathrm{kg}^{-1}\right][\mathrm{ppm}]$} \\
\hline Sc & $\begin{array}{c}25.0 \pm 1.8 \\
(5)\end{array}$ & $\begin{array}{c}15.6 \pm 0.6 \\
(4)\end{array}$ & $17 \pm 2.0$ \\
\hline $\mathrm{Y}$ & $\begin{array}{c}17.5 \pm 0.6 \\
(5)\end{array}$ & - & $20 \pm 2$ \\
\hline $\mathrm{La}$ & $\begin{array}{c}34.1 \pm 2.4 \\
(5)\end{array}$ & $\begin{array}{c}38.4 \pm 0.5 \\
(4)\end{array}$ & $39 \pm 6$ \\
\hline $\mathrm{Ce}$ & $\begin{array}{c}67.0 \pm 4.8 \\
(5)\end{array}$ & $\begin{array}{c}66.6 \pm 6.9 \\
(4)\end{array}$ & $68 \pm 7$ \\
\hline $\operatorname{Pr}$ & $8.17 \pm 0.67$ & - & $8.4 \pm 0.8$ \\
\hline $\mathrm{Nd}$ & $\begin{array}{c}32.4 \pm 2.4 \\
(5)\end{array}$ & $\begin{array}{c}34.6 \pm 2.9 \\
(4)\end{array}$ & $33 \pm 6$ \\
\hline $\mathrm{Sm}$ & $\begin{array}{c}5.67 \pm 0.45 \\
(5)\end{array}$ & $\begin{array}{c}5.28 \pm 0.48 \\
(4)\end{array}$ & $5.6 \pm 0.6$ \\
\hline $\mathrm{Eu}$ & $\begin{array}{c}1.53 \pm 0.04 \\
(5)\end{array}$ & $\begin{array}{c}1.48 \pm 0.03 \\
(4)\end{array}$ & $1.50 \pm 0.13$ \\
\hline Gd & $\begin{array}{c}4.91 \pm 0.44 \\
(5)\end{array}$ & - & $5.5 \pm 0.9$ \\
\hline $\mathrm{Tb}$ & $\begin{array}{c}0.70 \pm 0.07 \\
(5)\end{array}$ & $\begin{array}{c}0.59 \pm 0.13 \\
(4)\end{array}$ & $0.69 \pm 0.17$ \\
\hline Dy & $\begin{array}{c}4.05 \pm 0.05 \\
(5)\end{array}$ & - & $3.8 \pm 0.9$ \\
\hline Ho & $\begin{array}{c}0.77 \pm 0.09 \\
(5)\end{array}$ & - & $0.76 \pm 0.10$ \\
\hline Er & $\begin{array}{c}2.04 \pm 0.19 \\
(5)\end{array}$ & - & $2.2 \pm 0.5$ \\
\hline $\mathrm{Tm}$ & $0.30 \pm 0.02$ & $\begin{array}{c}1.13 \pm 0.40 \\
(4)\end{array}$ & $0.35 \pm 0.06$ \\
\hline $\mathrm{Yb}$ & $\begin{array}{c}1.95 \pm 0.22 \\
(5)\end{array}$ & $\begin{array}{c}2.17 \pm 0.30 \\
(4)\end{array}$ & $2.1 \pm 0.3$ \\
\hline $\mathrm{Lu}$ & $\begin{array}{c}0.28 \pm 0.03 \\
(5)\end{array}$ & $\begin{array}{c}0.34 \pm 0.04 \\
(4)\end{array}$ & $0.34 \pm 0.09$ \\
\hline
\end{tabular}

* Results are presented as: $\bar{x} \pm t_{0.05} s n^{-1 / 2}(n)$, where $\bar{x}$-arithmetic mean, $t_{0.05}$ - parameter of $t$-Student's distribution for significance level $\alpha=0.05$ and $n-1$ degrees of freedom, $n$ - number of determinations.

The number of determinations is given in the parenthesis.

$2.0)$, although the discrepancy is much smaller than that observed for INCT-TL-1. For all lanthanides the results are in moderate agreement with their certified values.

The INAA results for NCS DC73316 (see Table 8) are also good, except for those for thulium which are distinctly too high. ${ }^{170} \mathrm{Tm}$ has only one useful $\gamma$-ray line $(84.3 \mathrm{keV})$, the measurement of which because of high levels of Compton background may pose problems. This issue was also discussed in an earlier paper from this laboratory [15]. 


\section{Conclusions}

The accuracy of analytical results, i.e. "the closeness of agreement between a measured quantity value and the true quantity value of a measurand" [29], is of primary importance especially in trace analysis, where the possibilities and likelihood of making grave errors are especially acute and omnipresent [30]. Examples of the dispersion of analytical results in worldwide interlaboratory comparisons that sometimes exceeded several orders of magnitude were recently reviewed [31].

By the use of various instrumental methods, based on various physicochemical principles and CRMs, that are similar in terms of general composition and concentration levels of the analytes to that of the test samples, some of the systematic errors (if present) may be at least identified. When a thoroughly elaborated and tested method for the selective and quantitative isolation of an element or group of elements from the matrix is available, there is a good chance that potential interferences which are caused by the matrix will be eliminated or minimized. The elaborated new separation schemes for the isolation of REEs from biological and geological or environmental materials represent useful tools for verification of the accuracy of determination of this important group of elements, when employing instrumental methods like ICP-MS, INAA and others for routine analyses.

\section{References}

1. REE - Rare Earth Elements and their Uses. (2013). http://geology.com/articles/rare-earth-elements/.

2. Maestro, P., \& Huguenin, D. (1995). Industrial applications of rare earths: Which way for the end of the century. J. Alloy. Compd., 225, 520-528.

3. Prasada Rao, T., \& Kala, R. (2004). On-line and off-line pre-concentration of trace and ultra-trace amounts of lanthanides. Talanta, 63, 949-959.

4. Rollinson, H. R. (1995). Using geochemical data: Evaluation, presentation, interpretation. Harlow: Longman Group Ltd.

5. Hu, Z., Richter, H., Sparovek, G., \& Schung, E. (2004). Physiological and biochemical effects of rare earth elements on plants and their agricultural significance: a review. J. Plant Nutr., 27(1), 183-220.

6. Redling, K. (2008). Rare earth elements in agriculture with emphasis on animal husbandry. PhD Thesis, Ludwig Maximilian University of Munich, Germany.

7. Qiu, G., Li, W., Li, X., \& Zhou, W. (2005). Biological function of REE in plants and microbes. J. Rare Earth, 23, 645-652.

8. Qiu, G., Li, W., Li, X., Zhou, W., \& Yang, C. (2005). Biological intelligence of rare earth elements in animal cells. J. Rare Earth, 23, 554-573.

9. Dybczyński, R. S., Czerska, E., Danko, B., Kulisa, K., \& Samczyński, Z. (2010). Comparison of performance of INAA, RNAA and ion chromatography for the determination of individual lanthanides. Appl. Radiat. Isot., 68, 23-27.

10. Navarro, M. S., Ulbrich, H. H. G. J., Andrade, S., \& Janassi, V. A. (2002). Adaptation of ICP-OES routine determination techniques for the analysis of rare earth elements by chromatographic separation in geological materials: tests with reference materials and granitic rocks. J. Alloy. Compd., 344, 40-45.

11. Navarro, M. S., Andrade, S., Ulbrich, C. G., \& Girardi, V. A. V. (2008). The direct determination of rare earth elements in basaltic and related rocks using ICP-MS: Testing the efficiency of microwave oven sample decomposition procedures. Geostand. Geoanal. Res., 32, 167-180.

12. Zawisza, B., Pytlakowska, K., Feist, B., Polowniak, M., Kita, A., \& Sitko, R. (2011). Determination of rare earth elements by spectroscopic techniques: a review. J. Appl. At. Spectrom., 26, 2373-2390.

13. Minczewski, J., Chwastowska, J., \& Dybczyński, R. (1982). Separation and preconcentration methods in inorganic trace analysis. Chichester: Horwood Publishing Ltd.

14. Wasek, M., Kulisa, K., \& Dybczyński, R. (1996). A method for the determination of lanthanides in environmental and geological materials by neutron activation analysis after ion exchange pre-concentration. Chem. Anal., 41, 647-660.

15. Danko, B., Dybczyński, R. S., \& Samczyński, Z. (2008). Accurate determination of individual lanthanides in biological materials by NAA with pre- and post-irradiation separation. J. Radioanal. Nucl. Chem., 278, 81-88.

16. Strelow, F. W. E., \& Gricius, A. J. (1972). Separation of thorium from lanthanum and other elements by cation exchange chromatography at elevated temperatures. Anal. Chem., 44, 1898-1900.

17. Dybczyński, R. (1980). Comparison of the effectiveness of various procedures for the rejection of outlying results and assigning consensus values in interlaboratory programs involving determination of trace elements or radionuclides. Anal. Chim. Acta, 117, 53-70.

18. Bulska, E., Danko, B., Dybczyński, R. S., Krata, A., Kulisa, K., Samczyński, Z., \& Wojciechowski, M. (2012). Inductively coupled plasma mass spectrometry in comparison with neutron activation and ion chromatography with UV/VIS detection for the determination of lanthanides in plant materials. Talanta, 97, 303-311.

19. Dybczyński, R., \& Kulisa, K. (2005). Effect of temperature and the mechanism of zone spreading during cation-exchange separation of rare earth elements by ion chromatography. Chromatographia, 61, 573-579.

20. Dybczyński, R., Kulisa, K., Danko, B., \& Samczyński, Z. (2007). Accurate determination of trace amounts of lanthanum, yttrium and all stable lanthanides in biological materials by ion chromatography. Chem. Anal., 52, 549-564.

21. Samczyński, Z., \& Dybczyński, R. (1996). Ion exchange behavior of cadmium on amphoteric ion exchange resin and its application for the determination of cadmium in biological materials by neutron activation analysis. Chem. Anal., 41, 873-890.

22. Samczyński, Z., \& Dybczyński, R. (1997). Some examples of the use of amphoteric ion-exchange resins for the inorganic separations. J. Chromatogr. A, 789, 157-167.

23. Samczyński, Z., Danko, B., \& Dybczyński, R. (2000) Application of Chelex 100 ion exchange resin for separation of palladium, platinum and gold in geological and industrial materials by neutron activation analysis. Chem. Anal., 45, 843-857.

24. Samczyński, Z., \& Dybczyński, R. (2002). The use of Retardion 11A8 amphoteric ion exchange resin for the separation and determination of cadmium and zinc in geological and environmental materials by neutron activation analysis. J. Radioanal. Nucl. Chem., 254, 335-341. 
25. Samczyński, Z., \& Dybczyński, R. (2004). Ion exchange behavior of cadmium, mercury, silver and zinc on Retardion 11A8 and Chelex 100 ion exchangers in ammonia medium and its application for radiochemical separations. Microchim. Acta, 144, 103-114.

26. Samczyński, Z. (2006). Ion exchange behavior of selected elements on Chelex 100 resin. Solvent Extr. Ion Exch., 24(5), 781-794.

27. Samczyński, Z., Łyczko, M., Dybczyński, R., \& Narbutt, J. (2009). Ion exchange of the organometallic aqua-ion $\mathrm{fac}$ - $\left[{ }^{99 \mathrm{~m}} \mathrm{Tc}(\mathrm{CO})_{3}\left(\mathrm{H}_{2} \mathrm{O}\right)_{3}\right]^{+}$from aqueous solutions. Solvent Extr. Ion Exch., 27, 712-726.

28. Wasilewska, M., Goessler, W., Zischka, M., Maichinc, B., \& Knapp, G. (2002). Efficiency of oxidation in wet digestion procedures and influence from the residual organic carbon content on selected techniques for de- termination of trace elements. J. Anal. At. Spectrom., $17,1121-1125$.

29. ISO/IEC Guide 99:2007: International vocabulary of metrology - basic and general concepts and associated terms (VIM3). (2007). Geneva: International Organization for Standardization.

30. Dybczyński, R. (2002). Considerations on the accuracy of determination of some essential and/or toxic elements in biological materials. Chem. Anal., 47, 325-334.

31. Dybczyński, R. S., \& Polkowska-Motrenko, H. (2015). Certified reference materials in inorganic trace analysis. (Chapter 4). In I. Baranowska (Ed.), Handbook of trace analysis. Heidelberg: Springer Verlag $\mathrm{GmbH}$. 